\title{
Prevalence and risk factors of childbirth-related post-traumatic stress symptoms
}

Maryam Modarres ${ }^{1}$, Sedigheh Afrasiabi ${ }^{2}$, Parvin Rahnama ${ }^{3 *}$ and Ali Montazeri ${ }^{4^{*}}$

\begin{abstract}
Background: There is evidence that traumatic birth experiences are associated with psychological impairments. This study aimed to estimate the prevalence of childbirth-related post-traumatic stress symptoms and its obstetric and perinatal risk factors among a sample of Iranian women.

Methods: This was a cross-sectional study carried out in Bushehr, Iran during a 3-months period from July to September 2009. Data were collected from all women attending eleven healthcare centers for postnatal care 6 to 8 weeks after childbirth. Those who had a traumatic delivery were identified and entered into the study. In order to assess childbirth-related post-traumatic stress, the Post-traumatic Symptom Scale-Interview (PSS-I) was administered. Data on demographic, obstetric and perinatal characteristics also were collected. Multivariate logistic regression was performed to examine the association between childbirth-related post-traumatic stress and demographic and obstetric and perinatal variables.
\end{abstract}

Results: In all, 400 women were initially evaluated. Of these, 218 women (54.5\%) had a traumatic delivery and overall, 80 women (20\%) were found to be suffering from post-partum post-traumatic stress disorder (PTSD). Multiple logistic regression analysis revealed that post-partum PTSD was associated with educational level, gestational age at delivery, number of prenatal care visits, pregnancy complications, pregnancy intervals, labor duration, and mode of delivery.

Conclusions: The findings indicated that the prevalence of traumatic birth experiences and post-partum PTSD were relatively high among Iranian women. The findings also indicated that obstetric and perinatal variables were independently the most significant contributing factors to women's post-partum PTSD. It seems that a better perinatal care and supportive childbirth might help to reduce the burden of post-partum PTSD among this population.

\section{Background}

The post-traumatic stress disorder (PTSD) after childbirth was initially described by Bydlowski and Raoul-Duval [1]. Several studies indicated that childbirth is associated with post-traumatic stress disorder [2-5] and it can disrupt childcare in infancy [6]. In addition it has been shown that pregnancy occurrence after a traumatic birth experience may also result in the seek abortion, or request for unnecessary cesarean section in subsequent pregnancies $[7,8]$.

The PTSD is an anxiety disorder that can occur secondary to exposure to extreme events (stressors) that

\footnotetext{
*Correspondence: p_rahnama1381@yahoo.com; montazeri@acecr.ac.ir ${ }^{3}$ Department of Midwifery, Faculty of Nursing and Midwifery, Shahed University, Tehran, Iran

${ }^{4}$ Mental Health Research Group, Health Metrics Research Centre, Iranian Institute for Health Sciences Research, ACECR, Tehran, Iran

Full list of author information is available at the end of the article
}

are at outside of the usual range of human experience [9]. Childbirth is a physiologic and predictable event. Thus, the American Physiatrist Association was unable to classify childbirth as a traumatic disorder. However, since the Diagnostic and Statistical Manual of Mental Disorders-Revision 4 (DSM-IV) re-defined the criterion for a stressor, it was suggested that this new definition might also apply to childbirth as a traumatic event [9].

There is evidence that traumatic birth experiences are associated with post-traumatic stress disorder symptoms [10-12]. Studies have shown that different risk factors contribute to the development of post-partum PTSD including history of psychological problems, trait anxiety, obstetric procedures, negative aspects in staff-mother contact, sense of control, and social support $[5,13]$. Even, studies indicated that a history of trauma, in particular

\section{Biomed Central}


childhood sexual abuse (CSA), might be a risk factor for higher distress levels in pregnancy, and for post-partum post-traumatic stress symptoms $[14,15]$. In addition several studies revealed that the obstetrics factors and complicated deliveries were the most significant indicators of the post-partum PTSD [16-18]. However, if risk factors for PTSD were identified in pregnancy, primary prevention might be possible [2], and it could be prevented by support from health care providers.

Every year about $1,363,542$ women in Iran give birth [19]. Of these it is estimated that $35 \%$ of deliveries are cesarean sections and very likely subject to a traumatic birth [20]. There are limited reports about the postpartum PTSD in Iran [21,22]. Thus, the aim of present study was to estimate the prevalence of childbirthrelated post-traumatic stress symptoms and its obstetric and perinatal risk factors among a sample of Iranian women. By examining the risk factors associated with PTSD after childbirth health practitioners are better able to help with prevention or management of possible posttraumatic stress symptoms associated with childbirth.

\section{Methods}

\section{Design and data collection}

This was a cross sectional study carried out in Bushehr, Iran during a 3-months period from July to September 2009. Data were collected from all women attending eleven healthcare centers for postnatal care 6 to 8 weeks after childbirth. They were interviewed to indicate those who experienced a traumatic birth. One of us (SA) carried out all interviews in a private setting. Women who did not experience a traumatic delivery and those with stillbirth or neonatal deaths were excluded. Subsequently, the following questionnaires were completed for women who experienced a traumatic childbirth.

\section{Questionnaires}

1. A study specific questionnaire in order to collect data on demographic, obstetric and perinatal information.

2. The Post-traumatic Symptom Scale-Interview (PSS-I): This is a 17-items questionnaire that assesses PTSD symptoms based on the Diagnostic and Statistical Manual of Mental Disorders-Revision 4 (DSM-IV) [9]. It contains three subscales namely: re-experiencing, avoidance and increased arousal symptoms. Items are rated on $0-3$ scales for combined frequency and severity, yielding one score per item. A score of 0 corresponds to 'not at all'; 1 corresponds to 'once per week or less/a little'; 2 corresponds to '2 to 4 times per week/somewhat'; corresponds to ' 5 or more times per week/very much'. Severity scores for each of the re-experiencing, avoidance, and increased arousal subscales could be obtained by summing scores for items within each subscale. PTSD severity score could be obtained by summing all 17 items $[23,24]$. To make a diagnosis of post-partum PTSD, at least one re-experiencing item, three avoidance items and two increased arousal items should be present [9]. Validity of the Iranian version of PSS-I for PTSD screening is well documented [25].

\section{Analysis}

Participants were classified as with and without postpartum PTSD based on their PSS-I diagnosis. Descriptive statistics including chi-square were used to explore the data. Forward conditional multiple logistic regression analysis was performed to examine the association between dependent (post-partum PTSD) and independent variables. The level of significance was set at $5 \%$. The SPSS version 16 was used to analyze the data.

\section{Ethics}

The ethics committee of Tehran University of Medical Sciences approved the study. We obtained written informed consent from participants after comprehensive explanation of procedure involved.

\section{Results}

\section{The study sample}

In all 400 women were studied. Of these, 218 women (54.5\%) experienced a traumatic delivery. The mean age of participants $(\mathrm{n}=218)$ was $26.9(\mathrm{SD}=4.83)$ years. The mean number of children was $1.77(\mathrm{SD}=0.86)$, and 119 women $(54.6 \%)$ were experiencing their first childbirth. Thirty-four women (15.6\%) completed their formal education at higher level. Forty-nine women $(22.5 \%)$ had unwanted pregnancy; and 15 women (6.9\%) had less than 8 times prenatal care visits (lower than the routine care). There were 139 women (63.8\%) who had complicated pregnancy and 13 women (6.0\%) had hospital admissions due to these complications. The duration of labor was lower than 3 hours in 32 women (14.7\%), 67 women (30.7\%) had emergency cesarean section, 60 (27.5\%) had elective cesarean section, and 91 (41.7\%) had normal vaginal delivery. Eighteen women (8.3\%) had preterm deliveries and 14 women (6.4\%) have delivered low birth weight babies $(<2.5 \mathrm{~kg})$. Overall, 80 women (20\%) met the criteria for post-partum PTSD. Further analysis of the data showed that 131 women (60.1\%) were suffering from re-experiencing, 91 (41.7\%) from avoidance, and 120 (55.0\%) from increased arousal. The detailed results are shown in Table 1.

\section{Risk factors for post-partum PTSD}

The relationship between post-partum PTSD and independent variables was examined by performing forward conditional multiple logistic regression analysis. The 
Table 1 The characteristics of study sample

\begin{tabular}{|c|c|c|c|c|}
\hline & $\begin{array}{l}\text { Traumatic } \\
\text { birth } \\
(n=218)\end{array}$ & $\begin{array}{l}\text { With } \\
\text { PTSD } \\
(n=80) \\
\end{array}$ & $\begin{array}{l}\text { Without } \\
\text { PTSD } \\
(n=138)\end{array}$ & \\
\hline & & No (\%) & No (\%) & $\mathbf{P}$ \\
\hline Age groups (years) & & & & 0.80 \\
\hline$<20$ & $19(8.7)$ & $8(10.0)$ & $11(8.0)$ & \\
\hline $21-36$ & $189(86.7)$ & 69 (86.2) & $120(87.0)$ & \\
\hline$>36$ & $10(4.6)$ & $3(3.8)$ & $7(5.1)$ & \\
\hline Education & & & & 0.003 \\
\hline Primary & $85(39)$ & $38(47.5)$ & $47(34.1)$ & \\
\hline Secondary & $99(45.4)$ & $38(47.5)$ & $61(44.2)$ & \\
\hline Higher & $34(15.6)$ & $4(5.0)$ & $30(21.7)$ & \\
\hline Employment status & & & & 0.152 \\
\hline House wife & $196(89.9)$ & $5(6.2)$ & $17(12.3)$ & \\
\hline Employed & $22(10.1)$ & 75 (93.8) & $121(87.7)$ & \\
\hline Number of children & & & & 0.707 \\
\hline$>1$ & $99(45.4)$ & 35 (43.8) & $64(46.4)$ & \\
\hline 1 & $119(54.6)$ & $45(56.2)$ & $74(53.6)$ & \\
\hline $\begin{array}{l}\text { Pregnancy } \\
\text { was planned }\end{array}$ & & & & 0.007 \\
\hline Yes & $169(77.5)$ & $54(67.5)$ & $115(83.3)$ & \\
\hline No & $49(22.5)$ & $26(32.5)$ & $23(16.7)$ & \\
\hline $\begin{array}{l}\text { Gestational age } \\
\text { at delivery }\end{array}$ & & & & 0.001 \\
\hline Term & $200(91.7)$ & 67 (83.8) & $133(96.4)$ & \\
\hline Preterm & $18(8.3)$ & $13(16.2)$ & $5(3.6)$ & \\
\hline $\begin{array}{l}\text { Number of prenatal } \\
\text { care visits }\end{array}$ & & & & 0.004 \\
\hline$>10$ & $163(74.8)$ & $52(65.0)$ & $111(80.4)$ & \\
\hline $8-10$ & $40(18.3)$ & $17(21.2)$ & $23(16.7)$ & \\
\hline$<8$ & $15(6.9)$ & $11(13.8)$ & $4(2.9)$ & \\
\hline $\begin{array}{l}\text { Complications due } \\
\text { to pregnancy }\end{array}$ & & & & $<0.001$ \\
\hline Yes & $79(36.2)$ & $41(51.2)$ & $38(27.5)$ & \\
\hline No & $139(63.8)$ & $39(48.8)$ & $100(72.5)$ & \\
\hline $\begin{array}{l}\text { Admission due to } \\
\text { pregnancy } \\
\text { complications }\end{array}$ & & & & 0.012 \\
\hline Yes & $13(6.0)$ & $9(11.2)$ & $4(2.9)$ & \\
\hline No & $205(94.0)$ & 71 (88.8) & $134(97.1)$ & \\
\hline $\begin{array}{l}\text { Pregnancy } \\
\text { intervals (year) }\end{array}$ & & & & $<0.001$ \\
\hline$>2$ & $194(89.0)$ & $61(76.2)$ & $133(96.4)$ & \\
\hline$<2$ & $24(11.0)$ & 19 (23.8) & $5(3.6)$ & \\
\hline $\begin{array}{l}\text { Labor duration } \\
\text { in hours }\end{array}$ & & & & 0.007 \\
\hline Cesarean section & $127(58.3)$ & $54(67.5)$ & $73(52.9)$ & \\
\hline$>9$ & $20(9.2)$ & $10(12.5)$ & $10(7.2)$ & \\
\hline
\end{tabular}

Table 1 The characteristics of study sample (Continued)

\begin{tabular}{lllll}
\hline $3-9$ & $39(17.9)$ & $12(15.0)$ & $27(19.6)$ & \\
$<3$ & $32(14.7)$ & $4(5.0)$ & $28(20.3)$ & \\
Mode of delivery & & & & 0.006 \\
SVD & $91(41.7)$ & $26(37.5)$ & $65(47.1)$ & \\
ELCS & $60(27.5)$ & $19(23.8)$ & $41(29.7)$ & \\
EMCS & $67(30.7)$ & $35(43.8)$ & $32(23.2)$ & \\
Admission due to & & & & 0.10 \\
post-partum & & & & \\
complications & & & & \\
No & $204(93.6)$ & $72(90.0)$ & $132(95.7)$ & \\
Yes & $14(6.4)$ & $8(10.0)$ & $6(4.3)$ & \\
Sex of neonate & & & & \\
Male & $116(53.2)$ & $39(48.8)$ & $77(55.8)$ & \\
Female & $102(46.8)$ & $41(51.2)$ & $61(44.2)$ & \\
Birth weight (gr.) & & & & 0.068 \\
$<2500$ & $14(6.4)$ & $2(2.5)$ & $12(8.7)$ & \\
2500-4000 & $194(89.0)$ & $72(90.0)$ & $122(88.4)$ & \\
$>4000$ & $10(4.6)$ & $6(7.5)$ & $4(2.9)$ & \\
History of & & & & \\
child morbidity & & & & \\
Yes & $64(29.4)$ & $32(40.0)$ & $32(23.2)$ & \\
No & $154(70.6)$ & $48(60.0)$ & $106(76.8)$ & \\
\hline
\end{tabular}

diagnosis of post-partum PTSD was considered as outcome variable and all significant findings in univariate analyses were considered as independent factors. As shown in Table 2 the results indicated that education (OR for higher education $=0.15, \% 95 \mathrm{CI}=0.04-0.58$, $\mathrm{P}=0.006$ ), gestational age (OR for prematurity $=6.43, \%$ $95 \mathrm{CI}=1.78-23.24, \mathrm{P}=0.004$ ), number of prenatal care visits $(\mathrm{OR}$ for less than 8 times visits $=5.70, \% 95 \mathrm{CI}=$ 1.40-23.24, $\mathrm{P}=0.01)$, pregnancy complications $(\mathrm{OR}=$ $2.57, \% 95 \mathrm{CI}=1.26-5.22, \mathrm{P}=0.009$ ), pregnancy intervals (OR for less than 2 years $=9.08, \% 95 \mathrm{CI}=2.75-29.97$, $\mathrm{P}<0.001)$, duration of labor (OR for less than 3 hours = $0.11, \% 95 \mathrm{CI}=0.03-0.45, \mathrm{P}=0.002)$, and mode of delivery (OR for emergency cesarean section $=4.88, \% 95 \mathrm{CI}=$ 2.06-11.58, $\mathrm{P}<0.001$ ) were significant contributing factors to post-traumatic stress disorder after childbirth.

\section{Discussion}

The findings from present study indicated that more than half of women experienced a traumatic delivery. In addition we found that post-partum PTSD was associated with low educational level, premature labor, inadequate prenatal care visits, having complications due to pregnancy, pregnancy intervals less than 2 years, labor duration, and emergency cesarean section. 
Table 2 The results obtained from multiple logistic regression analysis indicating risk factors for post-partum PTSD ( $\mathbf{n}=\mathbf{2 1 8})$

\begin{tabular}{|c|c|c|}
\hline & OR $(95 \% \mathrm{Cl})$ & $\mathbf{P}$ \\
\hline \multicolumn{3}{|l|}{ Education } \\
\hline Primary & 1.0 (ref.) & \\
\hline Secondary & $0.56(0.26-1.18)$ & 0.13 \\
\hline Higher & $0.15(0.04-0.58)$ & 0.006 \\
\hline \multicolumn{3}{|l|}{$\begin{array}{l}\text { Gestational age } \\
\text { at delivery }\end{array}$} \\
\hline Term & 1.0 (ref.) & \\
\hline Preterm & $6.43(1.78-23.24)$ & 0.004 \\
\hline \multicolumn{3}{|c|}{$\begin{array}{l}\text { Number of prenatal } \\
\text { care visits }\end{array}$} \\
\hline$>10$ & 1.0 (ref.) & \\
\hline $8-10$ & $1.45(0.59-3.59)$ & 0.41 \\
\hline$<8$ & $5.70(1.40-23.24)$ & 0.01 \\
\hline \multicolumn{3}{|c|}{$\begin{array}{l}\text { Complications due } \\
\text { to pregnancy }\end{array}$} \\
\hline No & 1.0 (ref.) & \\
\hline Yes & $2.57(1.26-5.22)$ & 0.009 \\
\hline \multicolumn{3}{|c|}{ Pregnancy intervals } \\
\hline$>2$ & 1.0 (ref.) & \\
\hline$<2$ & $9.08(2.75-29.97)$ & $<0.001$ \\
\hline \multicolumn{3}{|l|}{$\begin{array}{l}\text { Labor duration } \\
\text { in hours }\end{array}$} \\
\hline Cesarean section & 1.0 (ref.) & \\
\hline$>9$ & $0.38(0.09-1.45)$ & 0.10 \\
\hline $3-9$ & $0.34(0.12-0.91)$ & 0.03 \\
\hline$<3$ & $0.11(0.03-0.45)$ & 0.002 \\
\hline \multicolumn{3}{|l|}{ Mode of delivery } \\
\hline SVD & 1.0 (ref.) & \\
\hline ELCS & $0.98(0.39-2.24)$ & 0.96 \\
\hline EMCS & $4.88(2.06-11.58)$ & $<0.001$ \\
\hline
\end{tabular}

There are many studies that investigated about postpartum PTSD [3,26-29]. For instance a study from Australia reported that out of 499 women $5.6 \%$ met the DSM-IV criteria for post-partum PTSD 4-6 weeks after birth [3]. Prevalence of post-traumatic stress symptoms after childbirth reported to be varying from $1.5 \%$ to $32.1 \%[26,27]$. However, this study found that 80 women (20\%) were suffering from post-partum PTSD. This high prevalence of post-partum PTSD might be explained by the fact that we assessed post-partum PTSD early after delivery. There is evidence that the prevalence of postpartum PTSD usually is high when assessed early after childbirth [3]. Other reasons for this high prevalence of post-partum PTSD might include: the instrument used to measure PTSD, the sample characteristics [5], prevalence of traumatic birth experiences, the way that health care professionals within hospitals treated the women, and finally the high rate of emergency cesarean section.

It has been shown that emergency cesarean section compared to elective cesarean section and normal vaginal delivery was more unpleasant birth experience and also was a risk factor for development of post-partum PTSD $[27,30]$. In fact is argued that emergency cesarean section can be an obstetric predictor of the development of post-partum PTSD $[3,16,30]$. In addition it has been shown that the emergency cesarean section was a risk factor for post-partum mental health problems [31]. There is evidence that women who undergo an emergency cesarean section have most negative cognitions and emotional feelings regarding delivery [32].

Unlike the study by Adewuya et al. that did not find any association between socio-demographic factors and post-partum PTSD [16], the findings of current study showed that level of education was a significant contributing factor to the outcome. In fact the results obtained from this study indicated that women with lower educational level were more likely to present with postpartum PTSD. The probability of reduced risk factor for post-partum PTSD in women with higher educational level compared to those with lower level higher was very meaningful (OR 0.15 vs. 1.0 respectively as shown in Table 2). Perhaps this finding is a pointer to the issue of educational inequalities that impacts women's health and as suggested at first instance it should be recognized and then be eliminated and if not at least be reduced [33].

Duration of labor and complications of pregnancy were found to be associated with post-partum PTSD. Studies showed that the increased medical interventions during labor, more intense pain in the first stage of labor and prolonged labor duration and perinatal complications similarly increase the likelihood of unfavorable birth experiences and consequently resulting in developing post-traumatic stress symptoms [27,34].

The finding from this study showed that preterm labor was associated with post-partum PTSD. Similarly, studies have reported that the birth of a premature infant was a predictor for the development of post-traumatic stress symptoms [35].

Prenatal care is an essential reproductive health service, and demonstrated that women who regularly see their health care providers during their pregnancy are less likely to expereince serious pregnancy complications [36]. The findings from present study also indicated that the number of prenatal care visits was associated with decreased post-partum PTSD. Perhaps women with increased prenatal care were more likely to receive additional support from health care providers and thus 
showed less post-partum PTSD. A study reported that reducing the number of antenatal care visits in low-risk pregnancies increases perinatal mortality in low- and middle-income countries [37]. It is argued that antenatal care is a preventive public health intervention designed to promote mother and infant health. However, Adewuya et al. found factors that independently associated with post-partum PTSD included hospital admission due to pregnancy complications, instrumental delivery, and emergency cesarean section, manual removal of placenta and poor maternal experience of control during childbirth [16]. Similarly, Soet et al. suggested that obstetric interventions may play a role in perceiving childbirth as traumatic, but other more personal or subjective factors have a mediating role in the subsequent development of post-traumatic stress symptoms [34].

Although unwanted pregnancy was significant factor in univariate analysis (see Table 1), its effect was diminished in the presence of other factors when performing forward conditional regression analysis. However, it has been suggested that unwanted pregnancy might be due to low-level health literacy, inappropriate contraception use, predominant male power, and even experience of traumatic events such as sexual abuse, or rape. As the result, it is obvious that in such situations post-partum PTSD would be expected and this is why we think empowering women should be a priority for public health interventions. Unfortunately we did not collect data on these and it would be helpful to consider such information in future studies.

In general, both fathers and mothers might be affected by a traumatic childbirth, but mothers are more vulnerable to PTSD, especially those who are unprivileged. Unfortunately in developing countries, there are few supporting services for women who exposed to a traumatic childbirth [38], although in some Muslim countries such as Iran family-based supports exist and women, to a large extent, are relying on such a support system and not official supporting services.

\section{Limitations}

This study had some limitations. Firstly, this was a cross-sectional study and thus the results should be interpreted with caution. Secondly, we only included demographic and obstetric and perinatal factors in the analysis, while post-partum PTSD symptoms may occur among women who have experienced a history of trauma regarding other factors including locus of control, perceptions of the mother-child relationship, partner attachment and perception of partner support. Also we obtained our sample from public health services, thereby excluding women who did not use any healthcare facilities. Finally, since women from different cultural backgrounds might show different patterns for post-partum PTSD, the results from this study could not be generalized to western women or even all women from Iran.

\section{Conclusion}

The findings indicated that the prevalence of traumatic birth experiences and post-partum PTSD were relatively high among Iranian women. The findings also indicated that obstetric and perinatal variables were independently the most significant contributing factors to women's post-partum PTSD. It seems that a better care, supportive childbirth, and attention paid to human rights for women might help to reduce the burden of post-partum PTSD among this population.

\section{Competing interests}

The authors declare that they have no competing interests.

\section{Authors' contributions}

MM supervised the study. SA was the main investigator, designed the study, and collected the data. PR helped the main investigator to analyze the data and wrote the first draft. AM contributed to the analysis, critically evaluated the paper, and provided the final draft. All authors read and approved the final revision of the manuscript.

\section{Acknowledgments}

The authors gratefully acknowledge the Institutional Review Board of the Tehran University of Medical Sciences for approving and supporting this project. We also wish to thank the participants for their cooperation.

\section{Author details}

${ }^{1}$ Department of Midwifery, Faculty of Nursing and Midwifery, Tehran University of Medical Sciences, Tehran, Iran. ${ }^{2}$ Department of Midwifery, Faculty of Nursing and Midwifery, Bushehr University of Medical Sciences, Bushehr, Iran. ${ }^{3}$ Department of Midwifery, Faculty of Nursing and Midwifery, Shahed University, Tehran, Iran. ${ }^{4}$ Mental Health Research Group, Health Metrics Research Centre, Iranian Institute for Health Sciences Research, ACECR, Tehran, Iran.

Received: 24 February 2012 Accepted: 31 August 2012

Published: 3 September 2012

\section{References}

1. Bydlowski M, Raoul-Duaval A: Un avatar psychique meconnu de la puerperalite: la nervrose traumatique post-obsetricale. [A psychological manifestation unknown within paediatrics: the posttraumatic obstetric neurosis]. Perspect Psychiatr 1978, 4:321-328.

2. Ayers S, Pickering AD: Do women get posttraumatic stress disorder as a result of childbirth? A prospective study of incidence. Birth 2001, 28:111-118.

3. Creedy DK, Shochet IM, Horsfall J: Childbirth and the development of acute trauma symptoms: incidence and contributing factors. Birth 2000, 27:104-111.

4. Czarnocka J, Slade P: Prevalence and predictors of post-traumatic stress symptoms following childbirth. Birth J Clin Psychol 2000, 39:35-51.

5. Olde E, van der Hart O, Kleber R, van Son M: Posttraumatic stress following childbirth: a review. Clin Psychol Rev 2006, 26:1-16.

6. Reynolds JL: Posttraumatic stress disorder after childbirth: the phenomenon of traumatic birth. Can Med Assoc J 1997, 156:831-835

7. Goldbeck-Wood S: Post-traumatic stress disorder may follow childbirth. BMJ 1996, 313:774

8. Ryding EL: Investigation of 33 women who demanded a cesarean section for personal reasons. Acta Obster Gynecol Scand 1993, 72:280-285.

9. American Psychiatric Association: Diagnostic and Statistical Manual of Mental Disorders. 4th edition. Washington, DC: American Psychiatric Association; 1994. 
10. Wijma K, Soderquist J, Wijma B: Posttraumatic stress disorder after childbirth: a cross sectional study. J Anxiety Disord 1997, 11:587-597.

11. Bailham D, Joseph S: Post-traumatic stress following childbirth: a review of the emerging literature and directions for research and practice. Psychology, Health \& Medicine 2003, 8:159-168.

12. Reynolds $\mathrm{J}$ : A prospective study of posttraumatic stress symptoms 1 months following childbirth in a group of 43 first time mothers. J Reprod Infant Psychol 1998, 16:91-105.

13. Menage J: Post-traumatic stress disorder in women who have undergone obstetric and/or gynaecological procedures. J Reprod Infant Psychol 1993, 11:221-228

14. Yampolsky L, Lev-Wiesel R, Ben-Zion IZ: Child sexual abuse: is it a risk factor for pregnancy? J Adv Nurs 2010, 66:2025-2037.

15. Lev-Wiesel R, Chen R, Daphna-Tekoah S, Hod M: Past traumatic events: are they a risk factor for high-risk pregnancy, delivery complications, and postpartum posttraumatic symptoms? J Womens Health 2009, 18:119-125.

16. Adewuya $\mathrm{AO}$, Ologun $\mathrm{YA}$, Ibigbami OS: Post-traumatic stress disorder after childbirth in Nigerian women: prevalence and risk factors. Obstet Gynecol: Int J; 2006:284-288

17. Ballard CG, Stanley AK, Brockington IF: PTSD after childbirth. Br J Psychiatry 1995, 166:525-528.

18. Fones C: Posttraumatic stress disorder occurring after painful childbirth. J Nerv Ment Dis 1996, 184:195-196.

19. Department of Economic and Social Affairs. New York: United Nations: 2009-2010 Demographic Yearbook; 2011.

20. Ahmad-Nia S, Delavar B, Eini-Zinab H, Kazemipour S, Mehryar AH, Naghavi M: Caesarean section in the Islamic Republic of Iran: prevalence and some sociodemographic correlates. East Mediterr Health J 2009, 15:1389-1398.

21. Taghizadeh Z, Jafar Beglou M, Arbabi M, Faghihzadeh S: The effect of counseling on post traumatic stress disorder after traumatic childbirth. HAYAT 2008, 13(4):23-31.

22. Modaress M, Mirmolaie ST, Rahimi Kian F, Afrasiabie S: An epidemiologic assessment of post traumatic stress disorder following childbearing. HAYAT 2011, 16(3-4):66-76.

23. Foa EB, Riggs DS, Dancu CV, Rothbaum BO: Reliability and validity of a brief instrument for assessing post-traumatic stress disorder. J Traumatic Stress 1993, 6:459-473.

24. Posttraumatic Symptom Scale-Interview Version (PSS-I) http://www.istss.org/ PosttraumaticSymptomScalelnterviewVersion.htm.

25. Mirzamani M, Mohammady MR, Besharat MA: Application of the PTSD scale in Iranian women. J Med Council of Islamic Republic of Iran 2006, 19:345-348

26. Adler J, Stadlmayr W, Tschudin S, Bitzer J: Post- traumatic symptoms after childbirth: what should we offer? J Psych Obstet Gynecol 2006, 27:107-112.

27. Maggioni C, Margola D, Filippi F: PTSD, risk factors, and expectations among women having a baby: A two-wave longitudinal study. J Psychosom Obst Gyn 2006, 27:81-90.

28. Söderquist J, Wijma B, Thorbert G, Wijma K: Risk factors in pregnancy for post-traumatic stress and depression after childbirth. BJOG 2009, 116:672-680.

29. McDonald S, Slade P, Spiby H, lles J: Post-traumatic stress symptoms, parenting stress and mother-child relationships following childbirth and at 2 years postpartum. J Psychosom Obstet Gynaecol 2011, 32:141-146.

30. Tham V, Christensson K, Ryding EL: Sense of coherence and symptoms of post-traumatic stress after emergency caesarean section. Acta Obstet Gynecol Scand 2007, 86:1090-1096.

31. Xie RH, Lei J, Wang S, Xie H, Walker M, Wen SW: Cesarean section and postpartum depression in a cohort of Chinese women with a high cesarean delivery rate. J Womens Health 2011, 20:1881-1886.

32. Ryding EL, Wijma K, Wijma B: Psychological impact of emergency cesarean section in comparison with elective cesarean section, instrumental and normal vaginal delivery. J Psychosom Obstet Gynecol 1998, 19:135-144.

33. WHO Commission on Social Determinants of Health: Closing the gap in a generation: health equity through action on the social determinants of health Final Report of the Commission on Social Determinants of Health. Geneva: World Health Organization; 2008.

34. Soet JE, Brack GA, Dilorio C: Prevalence and predictors of women's experience of psychological trauma during childbirth. Birth 2003, 30:36-46.
35. Holditch-Davis D, Bartlett TR, Blickman AL, Miles MS: Posttraumatic stress symptoms in mothers of premature infants. J Obstet Gynecol Neonatal Nurs 2003, 32:161-171.

36. Ayoola AB, Dowswell T, Carroli G, Duley L: Reducing the number of antenatal care visits in low-risk pregnancies increases perinatal mortality in low- and middle-income countries; women in all settings prefer the standard visit schedule. Evid Based Nurs 2011, 14:55-56.

37. Shaffer CF: Factors influencing the access to prenatal care by Hispanic pregnant women. J Am Acada Nurse Prac 2002, 14:93-96.

38. Brockington I: Diagnosis and management of post-partum disorders: a review. World Psychiatry 2004, 3:89-95.

doi:10.1186/1471-2393-12-88

Cite this article as: Modarres et al:: Prevalence and risk factors of childbirth-related post-traumatic stress symptoms. BMC Pregnancy and Childbirth 2012 12:88

\section{Submit your next manuscript to BioMed Central and take full advantage of:}

- Convenient online submission

- Thorough peer review

- No space constraints or color figure charges

- Immediate publication on acceptance

- Inclusion in PubMed, CAS, Scopus and Google Scholar

- Research which is freely available for redistribution 